\title{
Neurally Adjusted Ventilatory Assist Improves Patient-Ventilator Synchrony in a Patient With Tetanus and Unstable Diaphragmatic Electrical Activity
}

\author{
Natsuki Tane MD, Nao Okuda MD, Hideaki Imanaka MD PhD, and Masaji Nishimura MD PhD
}

\begin{abstract}
A 79-y-old man with generalized tetanus was admitted to the ICU. A left-forearm wound was surgically debrided, and the wound was closed. On postoperative day 1 , after the patient experienced opisthotonos and convulsions, endotracheal intubation was performed. Propofol and diazepam were infused but failed to stop the convulsions. Morphine, midazolam, dantrolene, and rocuronium were used to ameliorate the muscle spasms. Magnesium sulfate was also infused. On postoperative day 15 , patient-ventilator asynchrony was apparent. The patient showed recurrent tachypnea and bradypnea, which seemed typical of Cheyne-Stokes respiration. A neurally adjusted ventilatory assist (NAVA) catheter was inserted transnasally, and electrical activity of the diaphragm $\left(E_{d i}\right)$ was monitored. Readings showed regular attempts to breathe at 40-50 breaths/min with periodic changes in $\mathrm{E}_{\mathrm{di}}$ amplitude. NAVA mode improved patient-ventilator synchrony. Periodic breathing continued for 2 weeks. We stopped monitoring $\mathbf{E}_{\mathrm{di}}$ on postoperative day 39 . He began respiratory rehabilitation and was transferred to a hospital for rehabilitation on postoperative day 80 . We encountered periodic respiration in a patient with tetanus. $E_{\mathrm{di}}$ monitoring revealed periodic amplitude change. The cause of the periodic breathing pattern in this patient could not be determined but may be attributable to side effects of the pharmacologic interventions or the natural history of the disease itself. NAVA mode improved patient-ventilator synchrony. Key words: tetanus; periodic breathing; diaphragmatic electrical activity. [Respir Care 2015;60(4):e76-e79. () 2015 Daedalus Enterprises]
\end{abstract}

\section{Introduction}

Tetanus is a nervous system disorder characterized by muscle spasms. The most severe clinical form is generalized, life-threatening tetanus occurring in unvaccinated people. Patients with generalized tetanus exhibit tonic contraction of the skeletal muscles along with intermittent muscular spasms that give rise to the classic clinical man-

Drs Tane, Okuda, and Nishimura are affiliated with Emergency and Critical Care Medicine, and Dr Imanaka is affiliated with Emergency and Disaster Medicine, Tokushima University Hospital, Tokushima, Japan.

The authors have disclosed no conflicts of interest.

Correspondence: Masaji Nishimura MD PhD, Emergency and Critical Care Medicine, The University of Tokushima Graduate School, 3-18-15 Kuramoto, Tokushima, Japan 770-8503. E-mail: nmasaji@tokushimau.ac.jp.

DOI: $10.4187 /$ respcare. 03527 ifestations: stiff neck, opisthotonos, sardonic smile, rigid abdomen, and dysphagia. Vise-like contraction of the thoracic muscles and glottal or pharyngeal muscle contraction lead to apnea. ${ }^{1}$ However, periodic breathing is rarely reported. We observed periodic breathing with patient-ventilator asynchrony in a patient during mechanical ventilation and monitored electrical activity of the diaphragm $\left(\mathrm{E}_{\mathrm{di}}\right)$. NAVA mode triggered unstable diaphragmatic activity and improved patient-ventilator synchrony.

\section{Case Report}

A 79-y-old man with generalized tetanus was admitted to our ICU. Other than a lumber compression fracture, his medical history was nonspecific. He seemed to have contracted tetanus when he fell in the pond in his garden and injured his left forearm. Six days later, dysphagia and dysarthria became apparent. Tetanus was diagnosed, and he received human tetanus immunoglobulin $(500 \mathrm{U})$ and 


\section{NAVA Improves Patient-Ventilator Synchrony}

was transferred to our hospital for surgical treatment of the wound.

On admission, heart rate was 107 beats/min, and blood pressure was 136/82 $\mathrm{mm} \mathrm{Hg}$. Breathing frequency was 30 breaths/min, and $\mathrm{S}_{\mathrm{pO}_{2}}$ was $96 \%$ while breathing room air. Dysphagia and dysarthria manifested without any other neurological disorder. His left-forearm wound was surgically debrided, and the wound was closed, after which penicillin $\mathrm{G}(4,000,000 \mathrm{U})$ was administered 4 times/d. Human tetanus immunoglobulin $(2,750 \mathrm{U})$ was also administered. On postoperative day 1, after opisthotonos and convulsions developed, tracheal intubation was performed. Propofol and diazepam were infused but failed to stop the convulsions. Morphine (2 mg/h) and midazolam $(5 \mathrm{mg} / \mathrm{h})$ were then administered, along with dantrolene $(75 \mathrm{mg} / \mathrm{d})$ and rocuronium $(5 \mu \mathrm{g} / \mathrm{kg} / \mathrm{min})$, which ameliorated the muscle spasms. Rocuronium was continued for $45 \mathrm{~h}$. Dysautonomia caused fluctuations in blood pressure and heart rate. To remedy this, magnesium sulfate $(5 \mathrm{mEq} / \mathrm{h})$ was infused from postoperative days 7 to 16 . A tracheotomy was performed on postoperative day 9. Midazolam and morphine were discontinued on postoperative day 12 .

On postoperative day 15, patient-ventilator (Servo-i, Maquet, Wayne, New Jersey) asynchrony was apparent. While on pressure support ventilation, the patient showed recurrent tachypnea and bradypnea, which seemed typical of Cheyne-Stokes respiration. Upon closer observation, we doubted that breathing effort continued even during bradypnea because the ventilator did not trigger patient inspiratory effort. A NAVA catheter was inserted transnasally, and $\mathrm{E}_{\mathrm{di}}$ was monitored. Readings showed regular attempts to breathe at $40-50$ breaths/min but with periodic changes in $\mathrm{E}_{\mathrm{di}}$ amplitude (Fig. 1). When the diaphragmatic activity was great enough to trigger the ventilator, breath frequency was counted correctly by the monitor, but when it was too small to trigger the ventilator, bradypnea occurred. Even at a very sensitive trigger setting, the ventilator frequently failed to trigger with inspiratory efforts. In NAVA mode, the ventilator correctly triggered with inspiratory efforts, and patient-ventilator synchrony improved. Muscle spasms disappeared, and dantrolene was discontinued on postoperative day 28 .

Periodic breathing continued for 2 weeks (Fig. 2). We stopped monitoring $\mathrm{E}_{\mathrm{di}}$ on postoperative day 39 . The patient began respiratory rehabilitation and was transferred to a hospital for rehabilitation on postoperative day 80 .

\section{Discussion}

We treated a patient with general tetanus who exhibited periodic breathing on the ventilator graphics, with $\mathrm{E}_{\mathrm{di}}$ showing regular neurological intention to breathe. Respiratory failure in patients with tetanus has been attributed to suffocation caused by laryngospasm or to muscle stiffness or spasm of the abdominal wall, diaphragm, and chest wall. The incidence of periodic breathing in patients with tetanus remains unknown, and we have been unable to find previous reports on monitoring $\mathrm{E}_{\mathrm{di}}$ in tetanus patients.

The trigger function of the modern ventilator has improved, ${ }^{2}$ but a patient has to create sufficient inspiratory flow or pressure drop at the airway opening. Patients with COPD or neonates cannot create enough inspiratory flow or airway pressure drop, and patient-ventilator asynchrony is common. ${ }^{3,4}$ NAVA mode improves patientventilator synchrony in patients with COPD and neonates; however, it has not been reported to improve patient-ventilatory synchrony in patients with unstable $\mathrm{E}_{\mathrm{di}}$.

We could not be sure of the cause of the breathing pattern of our patient. We wondered whether dantrolene, rocuronium, and magnesium sulfate might be implicated. The half-life of dantrolene and rocuronium is $6 \mathrm{~h}$ and 145 min, respectively. We recognized periodic $\mathrm{E}_{\mathrm{di}}$ amplitude after $>5 \mathrm{~d}$ when we stopped these medications. Although the half-lives of these medications vary substantially in critically ill patients, the serum concentrations might be low enough. Dantrolene depresses excitationcontraction coupling in skeletal muscle by binding to the ryanodine receptor and decreasing the free intracellular calcium concentration. It may induce hypoventilation in $0.1-5.0 \%$ of cases and respiratory failure in $3.8 \%$ due to pleural effusion, pulmonary edema, and respiratory depression. ${ }^{5}$ The recovery time for surgical patients who take rocuronium for $>24 \mathrm{~h}$ is longer than for those who take it for $\leq 3 \mathrm{~h} .{ }^{6,7}$ Our patient took rocuronium for $48 \mathrm{~h}$. Magnesium sulfate has been used to control tetanus muscle spasms. ${ }^{8}$ It antagonizes calcium in the neuromuscular junction and myocardium, causing muscle weakness when serum levels reach between 20 and $34 \mathrm{mg} / \mathrm{dL} .{ }^{9}$ The maximum serum level of magnesium found in this patient was $6.2 \mathrm{mg} / \mathrm{dL}$. Although these 3 medications are known to induce muscle weakness, there have been no reports of periodic breathing associated with their use.

To obtain stable $\mathrm{E}_{\mathrm{di}}$, it is essential to keep the NAVA catheter in position. Because it is stiffer than a nasogastric tube, the catheter can move with ease. We secured it with elastic tape and hourly confirmed the inserted depth. The position was arbitrarily confirmed by abdominal x-ray. We do not think that the unstable $\mathrm{E}_{\mathrm{di}}$ was due to equipment failure or the NAVA catheter.

Cheyne-Stokes respiration is a typical periodic breathing pattern with repeat apnea and tachypnea. It is associated with cerebrovascular disease, brain tumor, meningitis, bridge-medullary damage, severe heart failure, uremia, and poisoning. Head computed tomography and magnetic resonance imaging showed no abnormal findings. According to the ventilator waveform, the breathing pattern was typical of Cheyne-Stokes respiration; however, $\mathrm{E}_{\mathrm{di}}$ monitor- 

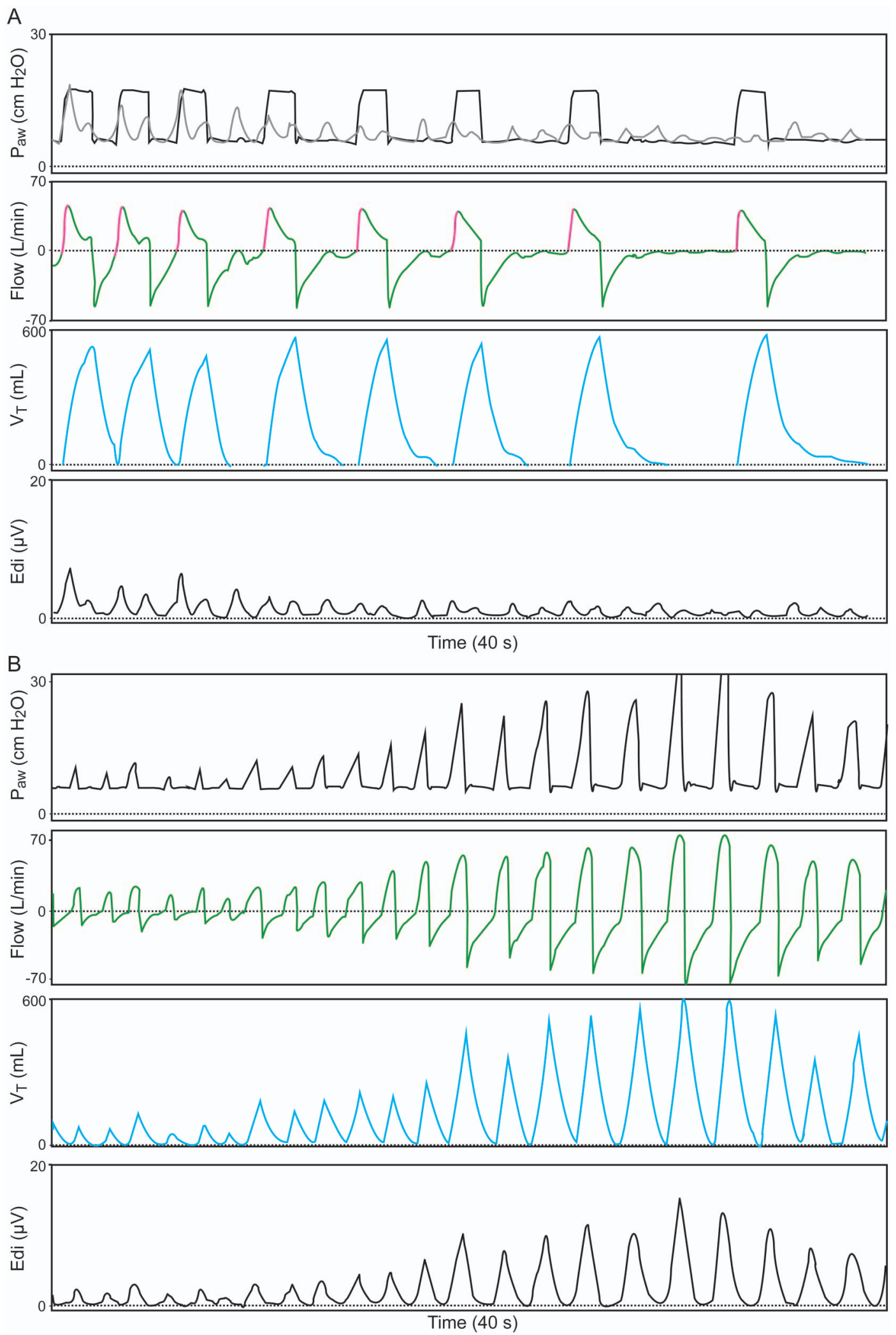

Fig. 1. A: Ventilator waveforms in pressure support ventilation mode. Breathing frequency (electrical activity of the diaphragm $\left[E_{d i}\right]$ shown in gray) was regular, but amplitude changed. The ventilator frequently missed triggers with inspiratory efforts. B: NAVA mode. $E_{d i}$ amplitude changed periodically, whereas the ventilator triggered with all inspiratory efforts, and patient-ventilator synchrony improved. $\mathrm{P}_{\text {aw }}=$ airway pressure; $\mathrm{V}_{\mathrm{T}}=$ tidal volume. 

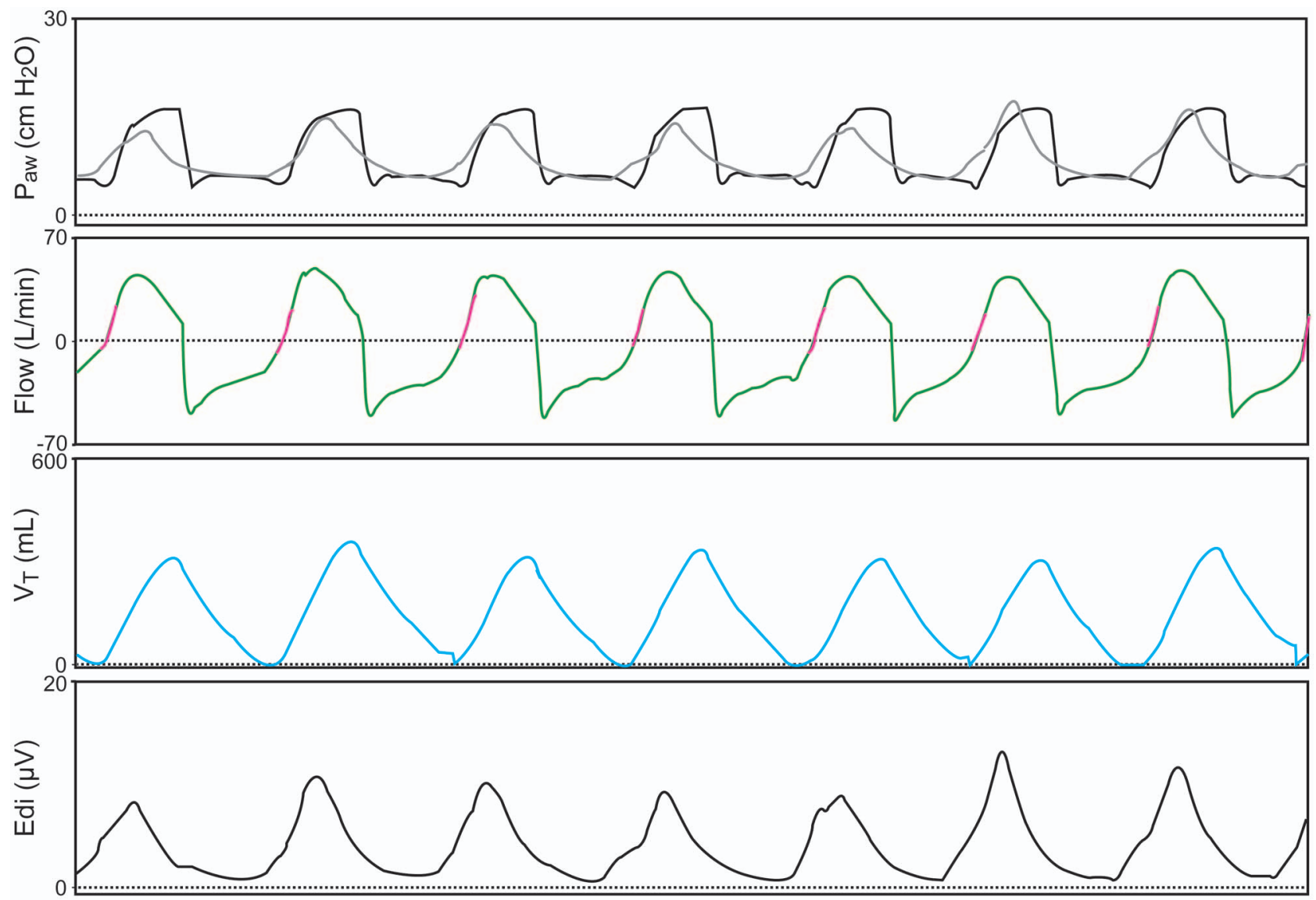

Time (12s)

Fig. 2. Waveforms in pressure support ventilation mode (electrical activity of the diaphragm $\left[\mathrm{E}_{\mathrm{di}}\right]$ shown in gray). A periodic pattern is not in evidence. The ventilator was triggered by all inspiratory efforts. $\mathrm{P}_{\mathrm{aw}}=$ airway pressure; $\mathrm{V}_{\mathrm{T}}=$ tidal volume.

ing showed that the patient was actually making regular attempts to breathe.

We encountered periodic respiration in a patient with tetanus. $\mathrm{E}_{\mathrm{di}}$ monitoring revealed periodic amplitude change. The cause of the periodic breathing pattern in this patient could not be determined, but it was likely due either to general tetanus or to the side effects of medications. NAVA mode improved patient-ventilator synchrony.

\section{REFERENCES}

1. Bunch TJ, Thalji MK, Pellikka PA, Aksamit TR. Respiratory failure in tetanus: case report and review of a 25 -year experience. Chest 2002;122(4):1488-1492.

2. Navalesi P, Costa R. New modes of mechanical ventilation: proportional assist ventilation, neurally adjusted ventilatory assist, and fractal ventilation. Curr Opin Crit Care 2003;9(1):51-58.

3. Sinderby C, Spahija J, Beck J, Kaminski D, Yan S, Comtois N, Sliwinski P. Diaphragm activation during exercise in chronic obstructive pulmonary disease. Am J Respir Crit Care Med 2001;163(7): 1637-1641.
4. Beck J, Reilly M, Grasselli G, Mirabella L, Slutsky AS, Dunn MS, Sinderby C. Patient-ventilator interaction during neurally adjusted ventilatory assist in low birth weight infants. Pediatr Res 2009;65(6): 663-668.

5. Brandom BW, Larach MG, Chen MS, Young MC. Complications associated with the administration of dantrolene 1987 to 2006: a report from the North American Malignant Hyperthermia Registry of the Malignant Hyperthermia Association of the United States. Anesth Analg 2011;112(5):1115-1123.

6. Nakatsuka H, Shimizu K, Sato T. Use of the muscle relaxant in the intensive care unit. Masui 2008;57(7):853-859.

7. Sparr HJ, Wierda JM, Proost JH, Keller C, Khuenl-Brady KS. Pharmacodynamics and pharmacokinetics of rocuronium in intensive care patients. Br J Anaesth 1997;78(3):267-273.

8. Thwaites CL, Yen LM, Loan HT, Thuy TT, Thwaites GE, Stepniewska $\mathrm{K}$, et al. Magnesium sulphate for treatment of severe tetanus: a randomised controlled trial. Lancet 2006;368(9545):1436-1443.

9. Mathew PJ, Muthurajan N, Wig J. Progressive muscle weakness with respiratory insufficiency in a young patient with tetanus during magnesium sulfate infusion. Acta Anaesthesiol Taiwan 2010;48(3): 152-154. 